\title{
Lumped Equivalent Models of Narrowband Antennas and Isolation Enhancement in a Three Antennas System
}

\author{
Anveshkumar NELLA, Abhay GANDHI \\ Dept. of ECE, VNIT, Nagpur, India \\ nellaanvesh@gmail.com, asgandhi@ece.vnit.ac.in \\ Submitted December 11, 2017 / Accepted July 5, 2018
}

\begin{abstract}
This paper initially discusses lumped equivalent models of narrowband (NB) antennas and then presents a technique to enhance isolation between UWB and NB antennas of the three antennas system. The proposed models are able to yield similar S-parameter performance as that of NB antennas at their resonant frequencies. Also, a good match is observed at other frequencies between the HFSS and AWR results. This paper reports an isolation enhancement technique using microstrip lines. The proposed approach enhances a minimum isolation of $11 \mathrm{~dB}$ at respective resonant frequencies. This paper also reports lumped equivalent models of dual band reject filters (DBRFs). Proposed geometry is fabricated and tested. Experimental result shows an agreement between the simulated and measured results.
\end{abstract}

\section{Keywords}

Band reject filter, dual bands, isolation, lumped equivalent model, microstrip lines

\section{Introduction}

In recent times, for cognitive radio (CR) technology, two-port planar integrated ultra wideband and frequency switching NB antenna structures [1-5] are attractive because of low cost, easy operation, required less space and compact nature. These structures adopt a UWB antenna for spectrum monitoring and one frequency reconfigurable narrowband antenna for communication. In these structures, switching is employed in the narrowband antennas to attain various operating frequencies using a single antenna. However, the reconfigurable mechanisms are having defects like non-linear effects of switches, negative effects of biasing circuitry, additional power requirements, and slow tuning [6], [7]. Sometimes, they need extra biasing circuitry or motors to obtain proper antenna reconfiguration [8]. Moreover, these systems are able to perform only one communication operation at a time. So, to reduce these constraints, we introduced the concept of multi-port integrated UWB and NB antennas systems in [6]. As an initial stage of exploring multi-port integrated UWB and NB antennas systems only two NB antennas are integrated on the UWB antenna substrate [9]. In this system, an UWB antenna, accessible at the first port (P1), is used for spectrum sensing and the two NB antennas, accessible at the remaining two ports (P2 and P3), are used for communication. This structure is able to perform a maximum of two communication tasks simultaneously because of two NB antennas. The proposed NB antennas are intended to perform communication without interfering Wi-Fi, Wi-MAX and ITU $8 \mathrm{GHz}$ bands in the UWB spectrum. These NB antennas attain dual bands in each case. In particular, the first narrowband antenna, linked at port 2 (P2), yields $6.5 \mathrm{GHz}$ and $9 \mathrm{GHz}$ bands while the second one, linked at port 3 (P3), achieves $7.5 \mathrm{GHz}$ and $9.5 \mathrm{GHz}$ bands. Isolation between the antennas is less than $19.5 \mathrm{~dB}$ over the complete UWB.

This paper initially reports lumped equivalent models of the NB antennas and then discusses a technique to enhance isolation between the UWB and NB antennas of the three antennas system [9]. The novelty introduced in the equivalent models is, designing lumped equivalent models of NB antennas using a conventional approach. Though the modeling of an antenna in its lumped equivalent model is difficult, this paper introduces equivalent models of NB antennas and DBRFs. The novelty introduced in the proposed system is, enhancing isolation using microstrip lines in a very closely spaced antennas system. In fact, enhancing isolation in a closely spaced antennas system is very challenging.

\section{Lumped Equivalent Models of NB Antennas}

It is well known that a microstrip antenna is also a distributed parameter network. So, this is an attempt to approximate the distributed model in terms of its lumped equivalent. A lumped equivalent model for a microstrip antenna can be derived from the conventional assumption of microstrip elements in terms of resistance $R$, inductance $L$, capacitance $C$ and conductance $G$ [10]. In antennas, any conducting element is approximated as a series combination of $R$ and $L$ because it exhibits a resistance $R$ and in- 
ductance $L$ due to the conductivity. The resistance $R$ represents conductor losses. In microstrip antennas, as the top and bottom conducting layers are separated by a dielectric material, a parallel combination of capacitance $C$ and conductance $G$ is assumed in shunt. It is obvious that some capacitance emerges when two conductors are separated by a dielectric material and $G$ is considered due to dielectric loss. Sometimes, a bit of inductance is also considered between the top and bottom layers to account fringing fields and surface waves. The consideration of this inductance results better accuracy in approximating the lumped equivalent model. This section initially presents a conventional approach of modeling a lumped equivalent model for a basic patch antenna as shown in Fig. 1. However, the radiating patch may be circular, trapezoidal, square or any other shape without slots and notches. Then, it discusses how the same approach is extended to the proposed NB antennas.

As mentioned earlier, in antennas each conducting element forms one series combination of $R$ and $L$. So, in the microstrip antenna, the three elements, i.e. microstrip feed line, radiating patch and ground layer also form three series combinations of $R$ and $L$. However, the series combination of $R$ and $L$ of ground layer is neglected due to negligible current flow than the top conductor. In the antenna, the top layer composes of two conducting elements as feed line and radiating patch. So, they form two separate parallel combinations of capacitance $C$ and conductance $G$ in shunt as shown in Fig. 2(a). However, the parallel combination of capacitance $C$ and conductance $G$ between the feed line and ground layer is also neglected since they constitute negligible $C$ and $G$. So, the resistance and inductance of the feed line and radiating patch are in series and hence they are added. After considering all the assumptions the final lumped equivalent model of the microstrip antenna is shown in Fig. 2(b).

In these models, the series combinations of $R 1, L 1$ and $R 2, L 2$ represent the lumped equivalent models of feed line and radiating patch, respectively. The parallel combinations of $G 1, C 1$ and $G 2, C 2$ represent the equivalent models between the feed line, ground plane and the radiating patch, ground plane, respectively. The resistance $R 3$ is $R 1+R 2$, and the inductance $L 3$ is $L 1+L 2$. The input port is terminated by $50 \Omega$ while the rectangular patch is terminated by the free space intrinsic impedance of $377 \Omega$.

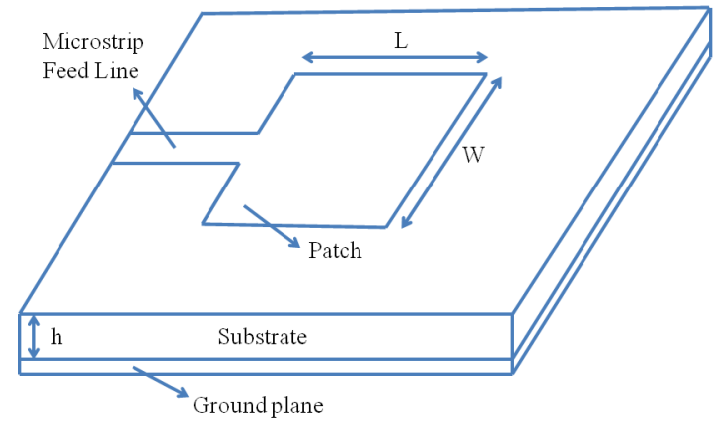

Fig. 1. Basic microstrip antenna with a microstrip line feed.

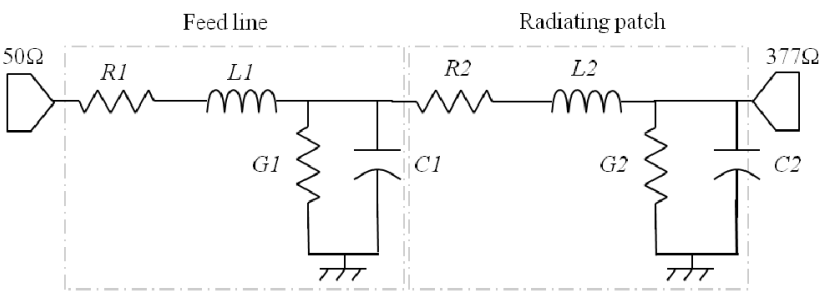

(a)

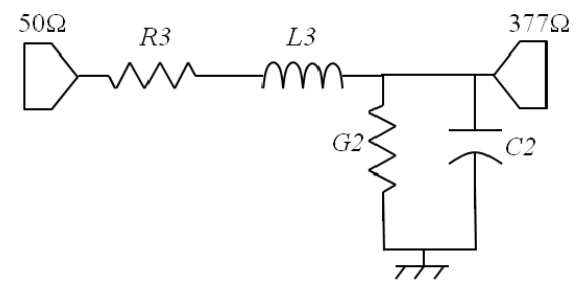

(b)

Fig. 2. Lumped equivalent model of a microstrip antenna (a) before assumptions, and (b) after assumptions.

In this paper, the proposed NB antenna equivalent models are simulated in AWR software. In each model, the component $(R, L, C$ and $G$ ) values are optimized in such a way that the model S-parameters match with the antenna $\mathrm{S}$-parameters at its resonant frequencies. However, at remaining frequencies there may be a mismatch because in the antenna the lumped component values $(R, L, C$ and $G)$ vary along with frequency whereas in the equivalent model the component values are fixed. So, at each and every frequency the model component values must be optimized to match with the antenna performance at those frequencies. This concept is applicable to all the lumped equivalent models. The models for UWB antennas are not studied since they yield high range of mismatch in S-parameter performance than narrowband antennas. Moreover, the models for UWB antennas are very difficult due to complex structures. As discussed in [9], in each NB antenna the two elements rectangular slotted patch and stub are responsible to yield upper and lower resonating bands, respectively. The dual bands are generated due to two diverse paths for currents after the feed line. So, in the lumped equivalent models the two diverse paths lead to a parallel combination after the feed line equivalent (series combination of $R 1$ and $L 1$ ) as shown in Fig. 3. The equivalent models for both the NB antennas are same since the structures are similar. However, the component values vary from antenna to antenna.

In this model, the series combinations of $R 1, L 1$ and $R 4, L 4$ represent the equivalent lumped models of the feed line and stub, respectively. The series combination of $R 3$,

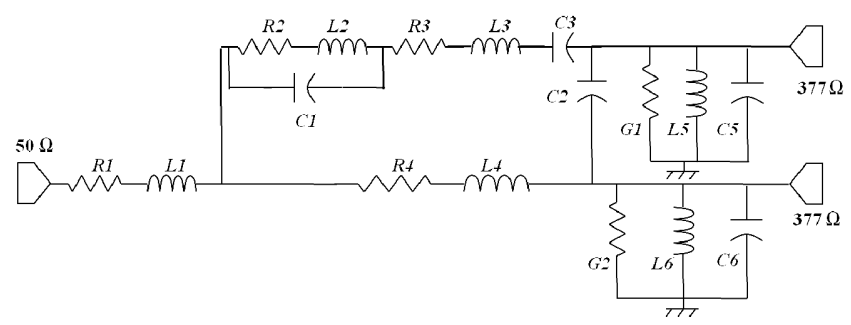

Fig. 3. Lumped equivalent model of the each NB antenna. 
$L 3$ and $C 3$ represents the rectangular slotted patch, where $C 3$ is the capacitance that emerges due to the rectangular slot. The series combination of $R 2$ and $L 2$ serves as a small feed line to the rectangular slotted patch. The capacitors $C 1$ and $C 2$ account the capacitances due to small gaps between the feed, rectangular slotted patch and the stub, rectangular slotted patch, respectively. The parallel combinations of $G 1, L 5, C 5$ and $G 2, L 6, C 6$ represent the equivalent models between the rectangular slotted patch, ground plane and the stub, ground plane, respectively. The inductors $L 5$ and $L 6$ account some inductance due to fringing fields and surface waves. Now, each model component values are carefully optimized for matching. The simulated S-parameters of the antennas and equivalent models are shown in Fig. 4.

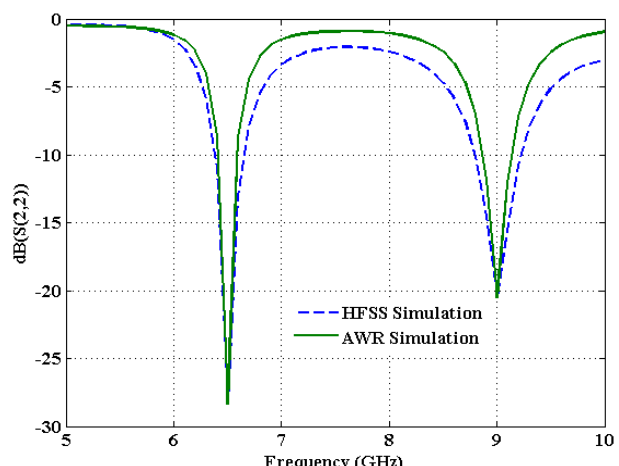

(a)

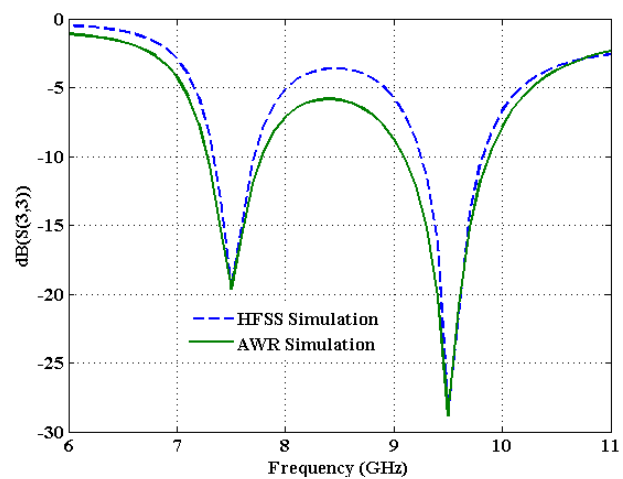

(b)

Fig. 4. Reflection coefficient plots, (a) the first NB antenna and (b) the second NB antenna.

\begin{tabular}{|c|c|c|c|c|c|c|c|c|}
\hline $\mathrm{R} 1$ & $\mathrm{~L} 1$ & $\mathrm{R} 2$ & $\mathrm{~L} 2$ & $\mathrm{R} 3$ & $\mathrm{~L} 3$ & $\mathrm{R} 4$ & $\mathrm{~L} 4$ & $\mathrm{C} 1$ \\
\hline 0.95 & 0.64 & 314 & 90.4 & 70.9 & 8.63 & 0.6 & 0.23 & 0.94 \\
$\Omega$ & $\mathrm{nH}$ & $\Omega$ & $1 \mathrm{nH}$ & $5 \Omega$ & $\mathrm{nH}$ & $\Omega$ & $\mathrm{nH}$ & $\mathrm{pF}$ \\
\hline $\mathrm{C} 2$ & $\mathrm{C} 3$ & $\mathrm{G} 1$ & $\mathrm{~L} 5$ & $\mathrm{C} 5$ & $\mathrm{G} 2$ & $\mathrm{~L} 6$ & $\mathrm{C} 6$ & \\
\hline 0.73 & 4.47 & 0.44 & 0.3 & 0.88 & 0.49 & 0.1 & 2.3 & \\
$\mathrm{pF}$ & $\mathrm{pF}$ & $\mathrm{m} \mho$ & $\mathrm{nH}$ & $\mathrm{pF}$ & $\mathrm{m} \mho$ & $6 \mathrm{nH}$ & $\mathrm{pF}$ & \\
\hline
\end{tabular}

Tab. 1. Optimized values of the first NB antenna lumped equivalent model.

\begin{tabular}{|c|c|c|c|c|c|c|c|c|}
\hline $\mathrm{R} 1$ & $\mathrm{~L} 1$ & $\mathrm{R} 2$ & $\mathrm{~L} 2$ & $\mathrm{R} 3$ & $\mathrm{~L} 3$ & $\mathrm{R} 4$ & $\mathrm{~L} 4$ & $\mathrm{C} 1$ \\
\hline 1.75 & 0.22 & 201 & 20.8 & $18 \Omega$ & 24.3 & 0.6 & 0.14 & 0.39 \\
$\Omega$ & $\mathrm{nH}$ & $\Omega$ & $3 \mathrm{nH}$ & & $7 \mathrm{nH}$ & $\Omega$ & $\mathrm{nH}$ & $\mathrm{pF}$ \\
\hline $\mathrm{C} 2$ & $\mathrm{C} 3$ & $\mathrm{G} 1$ & $\mathrm{~L} 5$ & $\mathrm{C} 5$ & $\mathrm{G} 2$ & $\mathrm{~L} 6$ & $\mathrm{C} 6$ & \\
\hline 0.43 & 5.28 & 5.88 & 0.27 & 0.91 & 2.35 & 0.21 & 1.55 & \\
$\mathrm{pF}$ & $\mathrm{pF}$ & $\mathrm{m} \mho$ & $\mathrm{nH}$ & $\mathrm{pF}$ & $\mathrm{m} \mho$ & $\mathrm{nH}$ & $\mathrm{pF}$ & \\
\hline
\end{tabular}

Tab. 2. Optimized values of the second NB antenna equivalent model.
From Fig. 4 it is evident that the equivalent models are yielding similar performances as that of NB antennas at resonant frequencies. The optimized values of each component in each model are shown in Tab. 1 and 2.

\section{Isolation Enhancement Using Microstrip Lines}

This section presents isolation enhancement using simple microstrip lines. The usual ways of enhancing isolation are, embedding different structures or slots between the radiating elements without altering the other performances. Various isolation enhancement techniques using slots, strips, CSRR, DGS, EBG and metamaterial structures are studied in [11-16]. However, isolation enhancement using microstrip lines suits well for the proposed system because of antennas placement and compact spacing between them. Moreover, other performances do not affect much with the integration of strip lines. In this approach four strip lines, in which a combination of two lines acts as a dual band reject filter (DBRF), are integrated between the radiating elements as shown in Fig. 5. They capture the fields crossing from one antenna to other result in reduction of mutual coupling. The dimensions of these lines are carefully optimized in the design software.

Figure 5 presents the DBRF structures along with the modified antennas dimensions. The dimensions of existing elements are slightly modified to get back the acceptable UWB and same resonating bands, which were changed due to the filters integration. The two strip lines between the two radiating elements form one DBRF. So, the proposed system consists of two DBRFs. The upper strip is responsible to capture the fields around upper resonating band

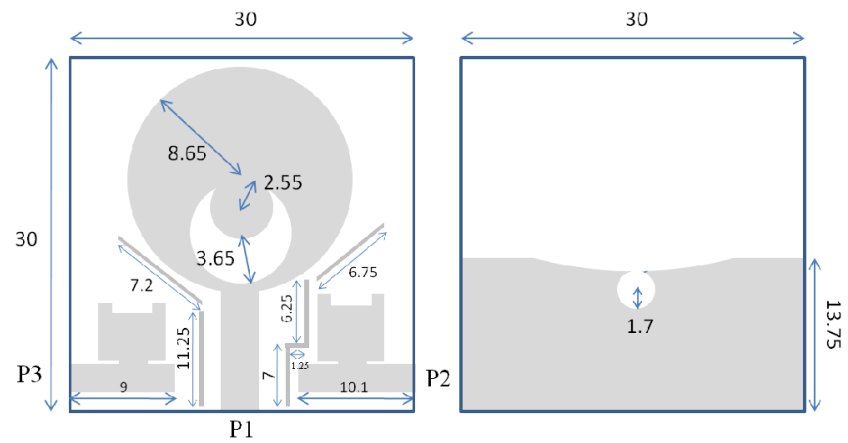

Fig. 5. The proposed integrated system with isolation enhancement structures.

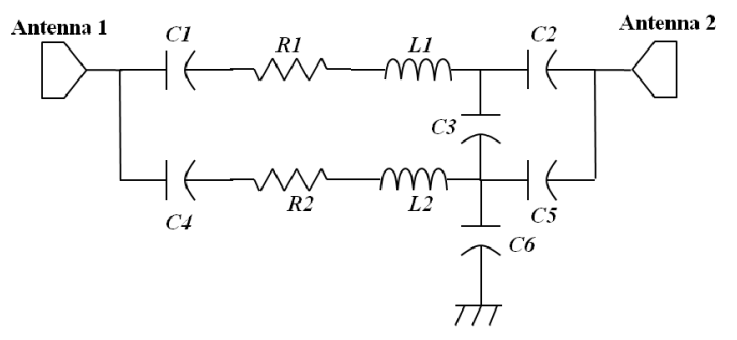

Fig. 6. Lumped equivalent model of each DBRF. 


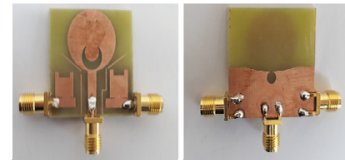

Fig. 7. Fabricated prototype of the proposed structure.

resulting into one band rejection. The lower strip captures the fields around lower resonating band resulting into another band rejection. Lumped equivalent model of the dual band reject filter is shown in Fig. 6 .

In this model, the upper and lower strip line equivalents also form a parallel combination. The series combinations of $R 1, L 1$ and $R 2, L 2$ represent the lumped equivalent models of the upper and lower strips, respectively. The capacitors $C 1$ and $C 4$ represent capacitances between the antenna element, upper strip and the antenna element, lower strip, respectively. The capacitors $C 2$ and $C 5$ represent capacitances between the upper strip, antenna element and the lower strip, antenna element. The capacitor $C 3$ represents capacitance between the upper and lower strips whilst the capacitor $C 6$ represents capacitance between the lower strip and ground plane. Since, the upper strip covers a small ground plane the capacitance between them is neglected. Fabricated prototype of the proposed system is shown in Fig. 7.

Now, this section discusses performance analysis of the proposed system in the two operative conditions as mentioned in [9]. It also reports effects of isolation enhancement structures on the system performance.

\subsection{Performance Analysis in the First Operative Condition}

In this case, the antennas at $\mathrm{P} 1, \mathrm{P} 2$ are excited and the antenna at $\mathrm{P} 3$ is terminated by a $50 \Omega$ matched termination. The UWB antenna operates in frequencies ranging from 2.64 GHz to $13.85 \mathrm{GHz}$ as shown in Fig. 8 .

From Fig. 8, it is obvious that the obtained band includes the UWB spectrum of $3.1 \mathrm{GHz}$ to $10.6 \mathrm{GHz}$. Peak gains of the proposed UWB antenna at various frequencies are shown in Fig. 9.

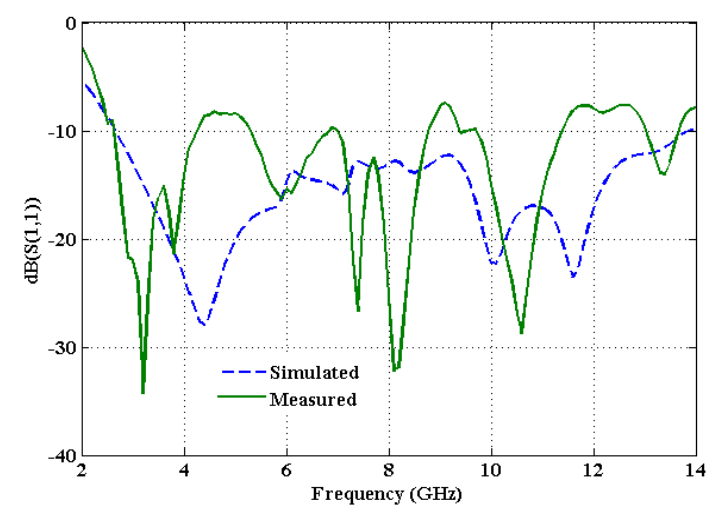

Fig. 8. Comparison of simulated and measured reflection coefficients of the proposed UWB antenna.

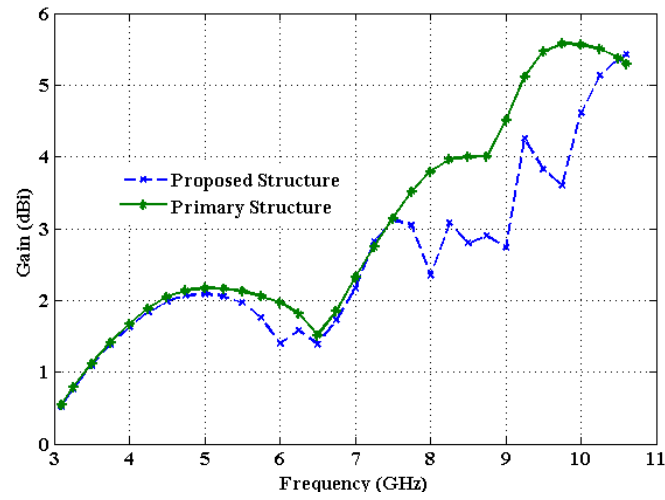

Fig. 9. Peak gain plot of the proposed UWB antenna.

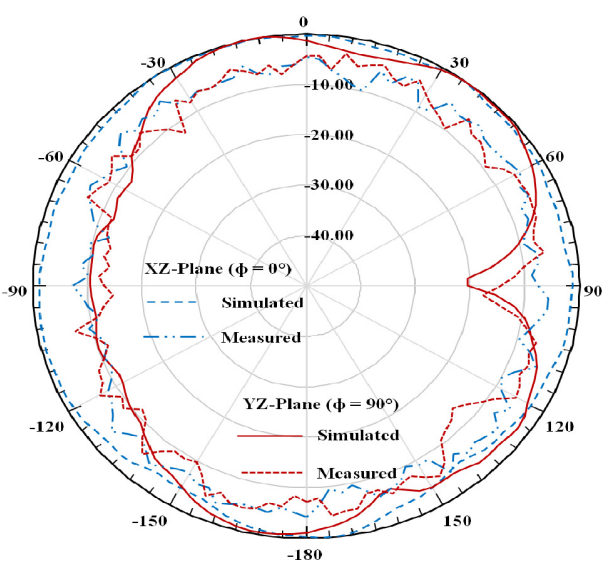

Fig. 10. 2-D radiation pattern of the proposed UWB antenna at $10.6 \mathrm{GHz}$

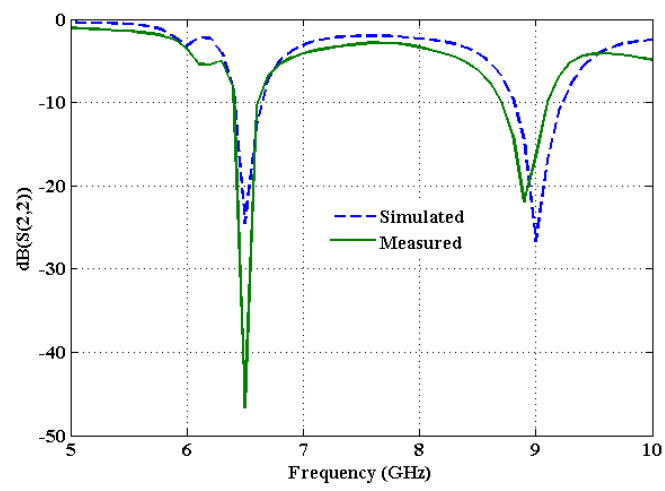

Fig. 11. Comparison of simulated and measured reflection coefficients of the proposed first NB antenna.

As it appears from Fig. 9, the peak gains at higher frequencies are reduced. This is mainly due to the attenuation caused by the introduced isolation enhancement structures. The maximum peak gain in the proposed structure is $5.42 \mathrm{dBi}$ at $10.6 \mathrm{GHz}$ whereas in the primary structure it is $5.58 \mathrm{dBi}$ at $9.75 \mathrm{GHz}$. The angular behavior of 2-D radiation pattern at $10.6 \mathrm{GHz}$ is shown in Fig. 10 .

The first NB antenna present at P2 achieves $6.5 \mathrm{GHz}$ and $9 \mathrm{GHz}$ bands with minimum return losses of $24.48 \mathrm{~dB}$ at $6.5 \mathrm{GHz}$ and $26.74 \mathrm{~dB}$ at $9 \mathrm{GHz}$ as shown in Fig. 11.

The angular behavior of 2-D radiation patterns at the resonant frequencies are shown in Fig. 12. 


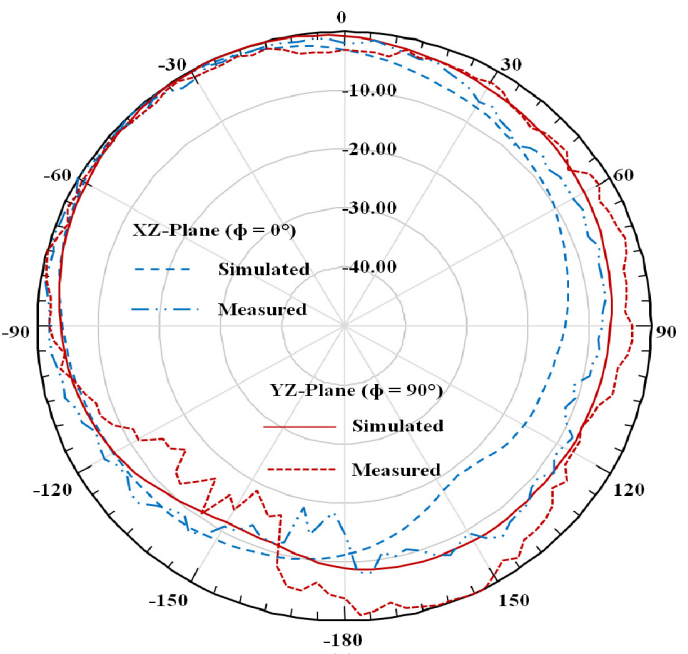

(a)

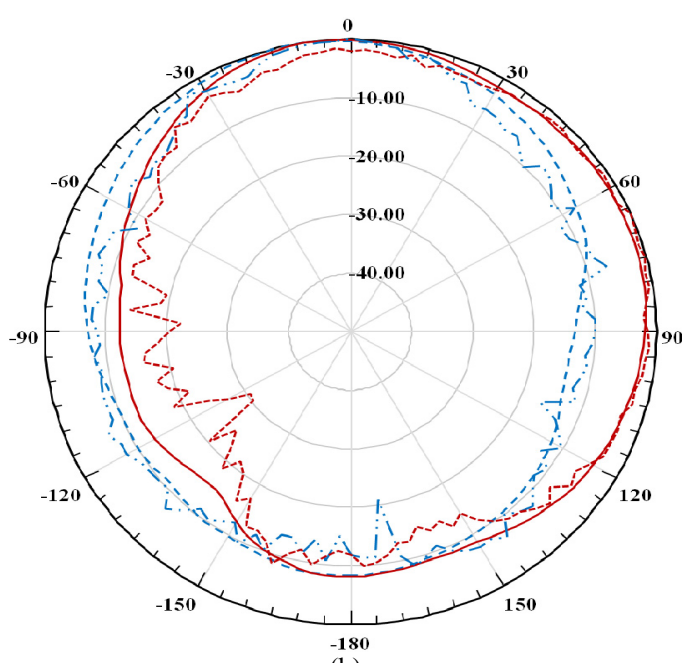

(b)

Fig. 12. 2-D radiation patterns of the proposed NB antenna at (a) $6.5 \mathrm{GHz}$ and (b) $9 \mathrm{GHz}$.

\begin{tabular}{|c|c|c|c|}
\hline \multicolumn{2}{|c|}{} & $\begin{array}{c}\text { Primary } \\
\text { Structure }\end{array}$ & $\begin{array}{c}\text { Proposed } \\
\text { Structure }\end{array}$ \\
\hline \multirow{2}{*}{$\begin{array}{c}\text { Peak Gain } \\
\text { (dBi) at }\end{array}$} & $\mathbf{6 . 5 ~ G H z}$ & 3.03 & 2.04 \\
\cline { 2 - 4 } & $\mathbf{9 ~ G H z}$ & 2.53 & 2.19 \\
\hline
\end{tabular}

Tab. 3. Comparison of simulated peak gains between the primary and proposed structures.

This antenna is achieving maximum gains of $2.04 \mathrm{dBi}$ and $2.19 \mathrm{dBi}$ at $6.5 \mathrm{GHz}$ and $9 \mathrm{GHz}$, respectively. Comparison of simulated peak gains between the primary and proposed structures is shown in Tab. 3.

From Fig. 12 and Tab. 3 it is clear that with the introduction of isolation enhancement structures gain is reduced but the radiation patterns are not distorted. This is also due to the DBRFs attenuation. The simulated and measured transmission coefficient plots of the proposed structure are shown in Fig. 13.

A clear comparison of simulated isolation between the primary and the proposed structures is shown in Tab. 4.

From Fig. 13 and Tab. 4 it is obvious that the introduced microstrip lines are able to enhance a minimum

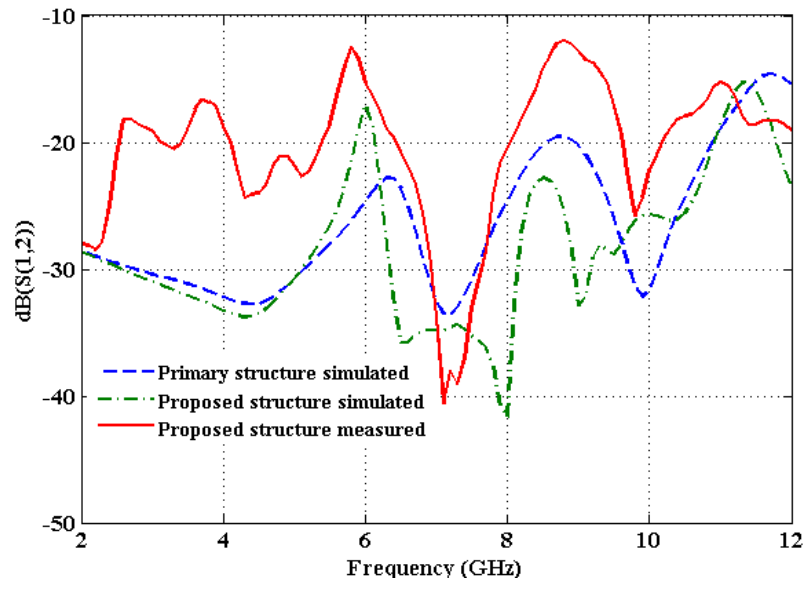

Fig. 13. Transmission coefficients between the UWB and the first NB antennas.

\begin{tabular}{|c|c|c|c|}
\hline & & $\begin{array}{l}\text { Primary } \\
\text { Structure }\end{array}$ & $\begin{array}{l}\text { Proposed } \\
\text { Structure }\end{array}$ \\
\hline \multirow{2}{*}{$\begin{array}{c}\mathrm{dB}(\mathrm{S}(1,2)) \\
\text { at }\end{array}$} & $6.5 \mathrm{GHz}$ & -23.64 & -35.81 \\
\hline & $9 \mathrm{GHz}$ & -20.28 & -32.84 \\
\hline
\end{tabular}

Tab. 4. Comparison of simulated isolation between the primary and the proposed structures.

isolation of $12 \mathrm{~dB}$ at respective resonant frequencies. It is also noted that each line is behaving like a BRF around the resonant frequency and the two lines between the two radiating elements form one DBRF.

\subsection{Performance Analysis in the Second Operative Condition}

In this case, the antennas at $\mathrm{P} 1, \mathrm{P} 3$ are excited and the antenna at $\mathrm{P} 2$ is terminated by a $50 \Omega$ matched termination. The UWB antenna operates in frequencies ranging from $2.68 \mathrm{GHz}$ to $13.79 \mathrm{GHz}$ as shown in Fig. 14.

The second NB antenna present at P3 achieves 7.5 GHz and $9.5 \mathrm{GHz}$ bands with minimum return losses of $23.77 \mathrm{~dB}$ at $7.5 \mathrm{GHz}$ and $18.21 \mathrm{~dB}$ at $9.5 \mathrm{GHz}$ as shown in Fig. 15.

The angular behavior of 2-D radiation patterns at the resonant frequencies are shown in Fig. 16.

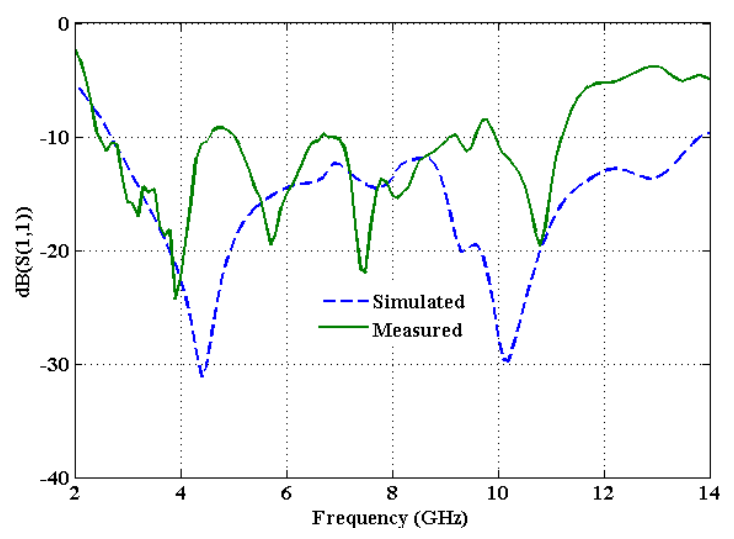

Fig. 14. Comparison of simulated and measured reflection coefficients of the proposed UWB antenna. 


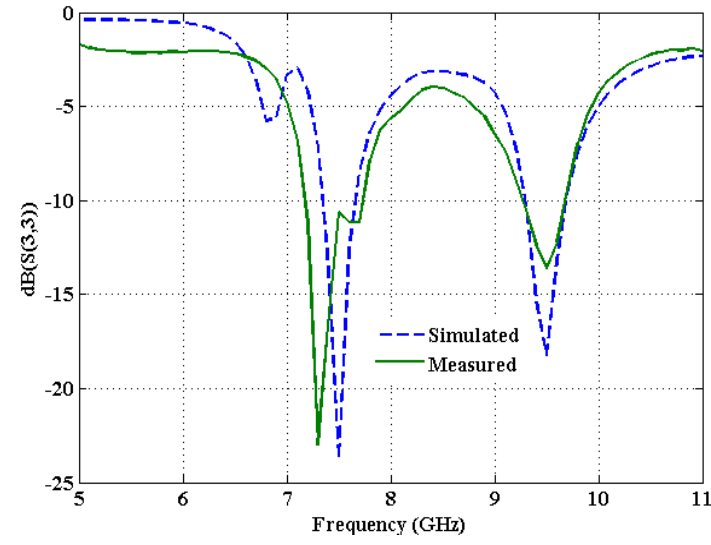

Fig. 15. Comparison of simulated and measured reflection coefficients of the proposed second NB antenna.

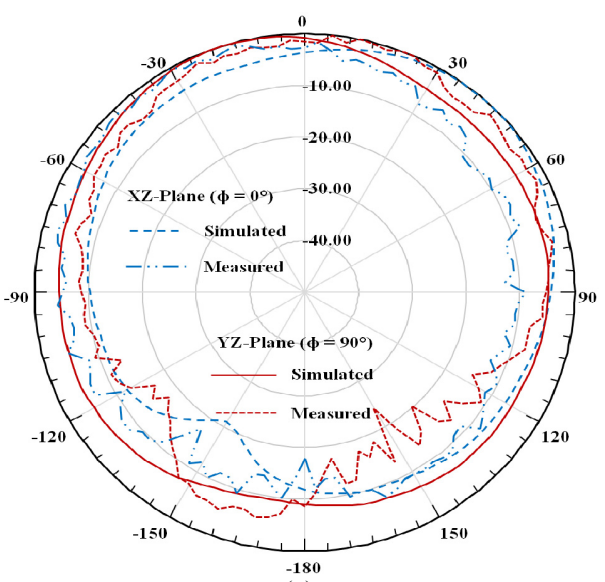

(a)

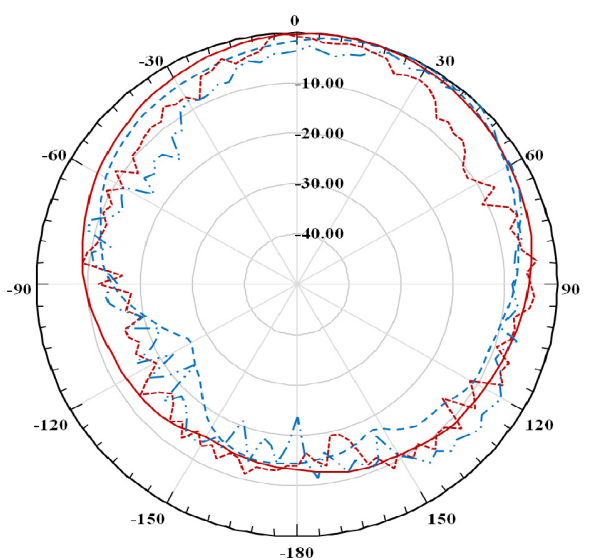

(b)

Fig. 16. 2-D radiation patterns of the proposed NB antenna at (a) $7.5 \mathrm{GHz}$ and (b) $9.5 \mathrm{GHz}$.

This antenna is achieving maximum gains of $1.84 \mathrm{dBi}$ and $3.43 \mathrm{dBi}$ at $7.5 \mathrm{GHz}$ and $9.5 \mathrm{GHz}$, respectively. Comparison of simulated peak gains between the primary and proposed structures is shown in Tab. 5 .

\begin{tabular}{|c|c|c|c|}
\hline \multicolumn{2}{|c|}{} & $\begin{array}{c}\text { Primary } \\
\text { Structure }\end{array}$ & $\begin{array}{c}\text { Proposed } \\
\text { Structure }\end{array}$ \\
\hline $\begin{array}{c}\text { Peak Gain } \\
\text { (dBi) at }\end{array}$ & $\mathbf{7 . 5 ~ G H z}$ & 3.64 & 1.84 \\
\cline { 2 - 4 } & $\mathbf{9 . 5 ~ G H z}$ & 3.2 & 3.43 \\
\hline
\end{tabular}

Tab. 5. Comparison of simulated peak gains between the primary and proposed structures.

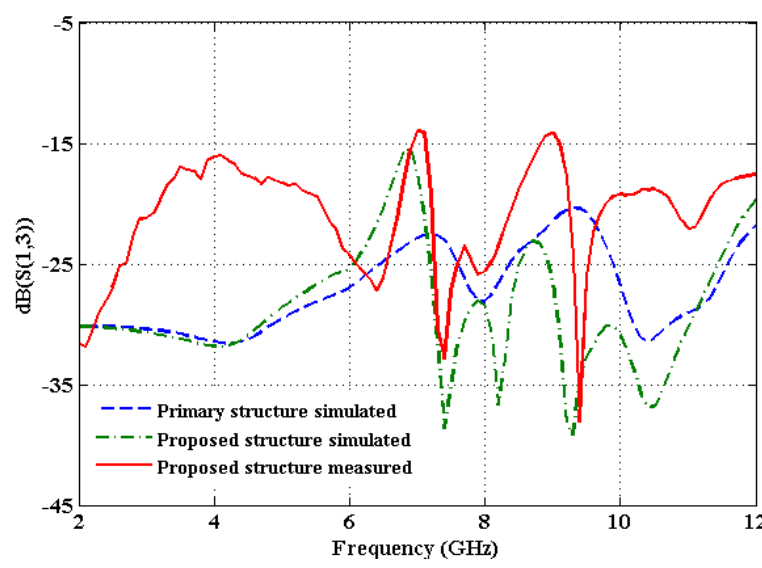

Fig. 17. Transmission coefficients between the UWB and the second NB antennas.

\begin{tabular}{|c|c|c|c|}
\hline \multicolumn{2}{|c|}{} & $\begin{array}{c}\text { Primary } \\
\text { Structure }\end{array}$ & $\begin{array}{c}\text { Proposed } \\
\text { Structure }\end{array}$ \\
\hline $\begin{array}{c}\text { dB(S(1,3)) } \\
\text { at }\end{array}$ & $\mathbf{7 . 5} \mathbf{~ G H z}$ & -23.87 & -35.17 \\
\cline { 2 - 4 } & $\mathbf{9 . 5 ~ G H z}$ & -20.77 & -32.71 \\
\hline
\end{tabular}

Tab. 6. Comparison of simulated isolation between the primary and the proposed structures.

In this case, the gain at $7.5 \mathrm{GHz}$ is reduced but interestingly at $9.5 \mathrm{GHz}$ it is enhanced. The simulated and measured transmission coefficient plots of the proposed structure are shown in Fig. 17.

A clear comparison of simulated isolation between the primary and the proposed structures is shown in Tab. 6 .

From Fig. 17 and Tab. 6 it is obvious that the introduced strips are able to enhance a minimum isolation of $11 \mathrm{~dB}$ at respective resonant frequencies. It is also noted that each strip is behaving like a BRF around the resonant frequency and the two strips between two radiating elements form one DBRF. Experimental result shows an agreement between the simulated and measured results. However, there are variations that may be due to fabrication faults, connector and cable losses. Simulated surface current distributions on the primary structure are shown in Fig. 18.

Simulated surface current distribution on the proposed structure is shown in Fig. 19.

It can observed from Fig. 19 that the upper strip of the left DBRF is capable of decoupling the currents induced into the second NB antenna at $9.5 \mathrm{GHz}$. This can be clearly understood by comparing Fig. 18(b) and 19. A comparison of isolation and edge to edge spacing between antennas of the proposed system with the existing systems is shown in Tab. 7. In the proposed system, the minimum edge to edge spacing between the UWB and the first NB antennas is $1.9 \mathrm{~mm}$ and the UWB and the second NB antennas is $2.65 \mathrm{~mm}$.

From Tab. 7, it is very clear that the proposed technique is able to enhance a minimum isolation of $11 \mathrm{~dB}$ at respective resonant frequencies in a very closely spaced antennas system. 


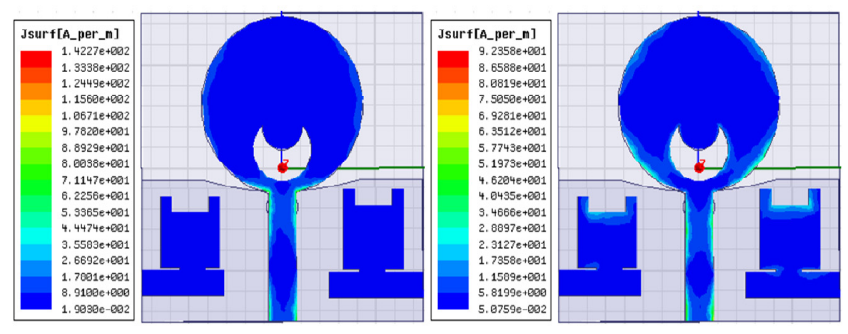

(a)

(b)

Fig. 18. Surface current distribution when only the UWB antenna is excited at, (a) $7.5 \mathrm{GHz}$ and (b) $9.5 \mathrm{GHz}$.

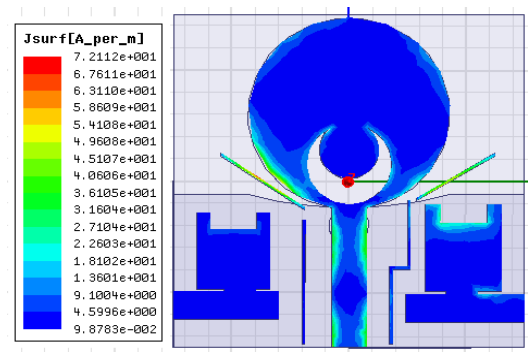

Fig. 19. Surface current distribution when only the UWB antenna is excited at $9.5 \mathrm{GHz}$.

\begin{tabular}{|c|c|c|c|}
\hline Ref. & Dimensions & $\begin{array}{c}\text { Edge to Edge } \\
\text { spacing }\end{array}$ & $\begin{array}{c}\text { Isolation } \\
\text { Improvement }\end{array}$ \\
\hline$[11]$ & $100 \mathrm{~mm} \times 50 \mathrm{~mm}$ & $\sim 13 \mathrm{~mm}$ & $14 \mathrm{~dB}$ and $4 \mathrm{~dB}$ \\
\hline$[13]$ & $54 \mathrm{~mm} \times 45 \mathrm{~mm}$ & $7 \mathrm{~mm}$ & $10 \mathrm{~dB}$ \\
\hline$[14]$ & $63.5 \mathrm{~mm} \times 40 \mathrm{~mm}$ & $8.6 \mathrm{~mm}$ & $16.5 \mathrm{~dB}$ \\
\hline$[15]$ & $78 \mathrm{~mm} \times 60 \mathrm{~mm}$ & $15 \mathrm{~mm}$ & $10 \mathrm{~dB}$ \\
\hline$[16]$ & $76.4 \mathrm{~mm} \times 91 \mathrm{~mm}$ & $10 \mathrm{~mm}$ & $6 \mathrm{~dB}$ \\
\hline $\begin{array}{c}\text { Proposed } \\
\text { system }\end{array}$ & $30 \mathrm{~mm} \times 30 \mathrm{~mm}$ & $\begin{array}{c}1.9 \mathrm{~mm} \text { and } \\
2.65 \mathrm{~mm}\end{array}$ & $>11 \mathrm{~dB}$ \\
\hline
\end{tabular}

Tab. 7. Comparison of isolation and edge to edge spacing.

\section{Conclusion}

This paper initially presented NB antenna lumped equivalent models. These models are exhibiting similar performance as that of NB antennas at their resonant frequencies. Moreover, at remaining frequencies also a good match is observed between the HFSS and AWR results. In this method, each equivalent model can have multiple combinations of values. However, to find out one correct combination, exact or approximate value of each component needs to be calculated. This is done by applying and solving the equations of distributed models. However, this is very difficult. Then, this paper reported an isolation enhancement technique using microstrip lines. In this approach, few microstrip lines are integrated between the radiating elements to decouple the energy. It is observed that each strip is behaving like a BRF. This method is capable of enhancing a minimum isolation of $11 \mathrm{~dB}$ at resonant frequencies. It is also clear that with the introduction of isolation enhancement structures gains are reduced but the radiation patterns are not distorted. The advantage of proposed technique is simple and yields better performance. This system can be used in applications like $4 \mathrm{G}$, body area networks, wireless personal networks, and wireless sensor networks due to compact and better performance.

\section{References}

[1] EBRAHIMI, E., KELLY, J. R., HALL, P. S. Integrated widenarrowband antenna for multi-standard radio. IEEE Transactions on Antennas and Propagation, 2011, vol. 59, no. 7, p. 2628-2635. DOI: 10.1109/TAP.2011.2152353

[2] TAWK, Y., CHRISTODOULOU, C. G. A new reconfigurable antenna design for cognitive radio. IEEE Antennas and Wireless Propagation Letters, 2009, vol. 8, p. 1378-1381. DOI: 10.1109/LAWP.2009.2039461

[3] SHARMA, S., TRIPATHI, C. C. An integrated frequency reconfigurable antenna for cognitive radio application. Radioengineering, 2017, vol. 26, no. 3, p. 746-754. DOI: 10.13164/re.2017.0746.

[4] TAWK, Y., COSTANTINE, J., HEMMADY, S., et al. Demonstration of a cognitive radio frontend using an optically pumped reconfigurable antenna system (OPRAS). IEEE Transactions on Antennas and Propagation, 2012, vol. 60, no. 2, p. 1075-1083. DOI: 10.1109/TAP.2011.2173139

[5] ERFANI, E., NOURINIA, J., GHOBADI, C., et al. Design and implementation of an integrated UWB/reconfigurable-slot antenna for cognitive radio applications. IEEE Antennas and Wireless Propagation Letters, 2012, vol. 11, p. 77-80. DOI: 10.1109/LAWP.2011.2182631

[6] NELLA, A., GANDHI, A. S. A survey on planar antenna designs for cognitive radio applications. Wireless Personal Communications, 2018, vol. 98, no. 1, p. 541-569. DOI: $10.1007 / \mathrm{s} 11277-017-4883-\mathrm{y}$

[7] RASLAN, A. R. Metamaterial Antennas for Cognitive Radio Applications. A Thesis Submitted to the Electronics Engineering Department, American University in Cairo School of Sciences and Engineering in 2013.

[8] CHRistodoulou, C. G., TAWK, Y., LANE, S. A., et al. Reconfigurable antennas for wireless and space applications. In Proceedings of the IEEE, 2012, vol. 100, no. 7, p. 2250-2261. DOI: 10.1109/JPROC.2012.2188249

[9] KUMAR, N. A., GANDHI, A. S. A compact novel three-port integrated wide and narrow band antennas system for cognitive radio applications. International Journal of Antennas and Propagation, 2016, article ID 2829357, p. 1-14. DOI: $10.1155 / 2016 / 2829357$

[10] POZAR, D. M. Microwave Engineering. $2^{\text {nd }}$ ed. New York (USA): Wiley \& Sons, Inc, 1998.

[11] NUMAN, A. B., SharaWI, M. S., STeFFES, A., ALOI, D. N. A defected ground structure for isolation enhancement in a printed MIMO antenna system. In Proceedings of the 7th European Conference on Antennas and Propagation (EuCAP). Gothenburg (Sweden), 2013, p. 2123-2126.

[12] ZHU, J., FENG, B., DENG, L., LI, S. Ultrawideband $\mathrm{MIMO}$ /diversity antenna using CSRR structure for isolation enhancement. In Proceedings of the IEEE 4th Asia-Pacific Conference on Antennas and Propagation (APCAP). Bali Island (Indonesia), 2015, p. 27-29. DOI: 10.1109/APCAP.2015.7374258

[13] ALSATH, M. G. N., KANAGASABAI, M., BALASUBRAMANIAN, B. Implementation of slotted meander-line resonators for isolation enhancement in microstrip patch antenna arrays. IEEE Antennas and Wireless Propagation Letters, 2013, vol. 12, p. 15-18. DOI: 10.1109/LAWP.2012.2237156 
[14] HABASHI, A., NOURINIA, J., GHOBADI, C. A rectangular defected ground structure for reduction of mutual coupling between closely spaced microstrip antennas. In Proceedings of the IEEE 20th Iranian Conference on Electrical Engineering (ICEE). Tehran (Iran), 2012, p. 1347-1350. DOI 10.1109/IranianCEE.2012.6292566

[15] BAIT-SUWAILAM, M. M., SIDDIQUI, O. F., RAMAHI, O. M. Mutual coupling reduction between microstrip patch antennas using slotted-complementary split-ring resonators. IEEE Antennas and Wireless Propagation Letters, 2010, vol. 9, p. 876-878. DOI: 10.1109/LAWP.2010.2074175

[16] YANG, X. M., LIU, X. G., ZHOU, X. Y., et al. Reduction of mutual coupling between closely packed patch antennas using wave guided metamaterials. IEEE Antennas and Wireless Propagation Letters, 2012, vol. 11, p. 389-391. DOI: 10.1109/LAWP.2012.2193111

\section{About the Authors ...}

Anveshkumar NELLA was born in 06/03/1991. He received is B.Tech degree from SSIT, Hyderabad, India. He received is M.Tech degree from VNIT, Nagpur, India, in the field of Communication Systems Engineering. Currently, he is pursuing Ph.D in VNIT, ECE. His research fields include planar antennas, radars, and RF circuits. He published three papers in SCI journals and 5 papers in IEEE conferences.

Abhay GANDHI received his BE (Electronic Engg.) in 1989 from VRCE, Nagpur and ME (ECE) from the Indian Institute of Science, Bangalore in 1991. He completed his Ph.D degree in August 2002. His research interests include wireless communications, RF circuit design and radars. He has published more than 40 research papers, mostly in $\mathrm{SCI} / \mathrm{Scopus}$ journals and international conferences. One of the research papers co-authored by him has received "Best paper award" at Global Wireless Summit (Wireless VITAE) held in June 2013 at Atlanta City, USA. He visited San Francisco, USA in Oct 1995 to present a paper at an international conference ISSSE'95. 